\title{
Identification of gene markers associated with metastasis in clear cell renal cell carcinoma
}

\author{
HAILING YANG ${ }^{1}$, PENGFEI HUO $^{2}$, GUOZHANG HU$^{1}$, BO WEI $^{3}$, DALIAN KONG $^{4}$ and HONGJUN LI $^{5}$ \\ ${ }^{1}$ Emergency Department; ${ }^{2}$ Intensive Care Unit; Departments of ${ }^{3}$ Neurosurgery and ${ }^{4}$ Orthopedics; \\ ${ }^{5}$ Health Examination Center, China-Japan Union Hospital, Jilin University, Changchun, Jilin 130033, P.R. China
}

Received September 18, 2015; Accepted January 31, 2017

DOI: $10.3892 / \mathrm{ol} .2017 .6084$

\begin{abstract}
The present study aimed to screen potential target genes for the early diagnosis and treatment of early metastatic clear cell renal cell carcinoma (ccRCC) using the microarray data of early metastatic and non-metastatic ccRCC samples. The DNA microarray dataset GSE47352 was downloaded from Gene Expression Omnibus and included 4 early metastatic and 5 non-metastatic ccRCC samples. Differentially expressed genes (DEGs) were screened using the limma package. Then, pheatmap package was used to conduct two-way clustering for the DEGs. Subsequently, MAPPFinder and GenMAPP were employed separately to perform functional and pathway enrichment analysis for the DEGs. Additionally, a protein-protein interaction (PPI) network was constructed using Cytoscape, and small drug molecules were searched using Connectivity map (cmap). In total, 196 upregulated and 163 downregulated genes were identified. DEGs, including JUN, tumor necrosis factor (TNF), Ras homolog family member B (RHOB) and transforming growth factor $\beta 2$ (TGF $\beta 2$ ) were significantly enriched in the signaling pathway of renal cell carcinoma. Furthermore, nuclear receptor subfamily 4 group A member 1 (NR4A1) was significantly enriched in the mitogen-activated protein kinase signaling pathway; in addition, laminin subunit $\alpha$ (LAMA) 1, LAMA2 and LAMA4 were significantly enriched in extracellular matrix-receptor interaction. JUN (degree $=6$ ) had the highest degree in the PPI network. Thapsigargin (score $=-0.913$ ) possessed the highest performance in terms of the treatment of early metastatic ccRCC. In the present study, it was discovered that certain DEGs, including JUN, TNF, RHOB, NR4A1, TGF 32 , LAMA1, LAMA2 and LAMA4 were potential target genes associated with early metastatic ccRCC.
\end{abstract}

Correspondence to: Dr Hongjun Li, Health Examination Center, China-Japan Union Hospital, Jilin University, 126 Sendai Street, Changchun, Jilin 130033, P.R. China

E-mail: lihongjune 1960@126.com

Key words: clear cell renal cell carcinoma, differentially expressed genes, functional and pathway enrichment, protein-protein interaction network, small drug molecule
In addition, thapsigargin could be used as an efficient small drug molecule for the treatment of early metastatic ccRCC.

\section{Introduction}

Renal cell carcinoma (RCC), which is one of the most common types of cancer, accounts for almost $3 \%$ of all human malignancies (1). As the most common type of RCC, clear cell RCC (ccRCC) accounts for 70-80\% of RCC cases (2). The metastasis and recurrence of ccRCC, as well as its poor prognosis, results in poor survival for patients (3).

At present, with the development of microarray technology, a large number of differentially expressed genes (DEGs) associated with ccRCC have been identified and the genes expression profiles have been uploaded to databases, including Gene Expression Omnibus (GEO) and Array Express Archive for researchers to study $(4,5)$. Many genes and signaling pathways involved in the metastasis of ccRCC have been discovered. Downregulation of FOXO3a may promote tumor metastasis in ccRCC (6). C-X-C motif chemokine receptor 2 (CXCR2)/CXCR2 ligand biology is important in the promotion of angiogenesis and facilitation of tumor growth and metastasis in RCC cells (7). A previous study demonstrated that overexpression of brain-type fatty-acid-binding protein (FABP) may lead to the reduction of liver-type FABP in $\mathrm{RCC}$, which serves a role in cell signaling, regulation of gene expression, cell growth and differentiation (8). Although the above researches have identified specific genes associated with metastasis of ccRCC, the mechanisms of ccRCC metastasis remain unclear. Furthermore, few drugs have been developed to be effective for treatment of metastatic ccRCC.

In the present study, in order to achieve an improved understanding of ccRCC, early metastatic and non-metastatic ccRCC samples were used to screen DEGs associated with metastatic ccRCC. Ni et al (6) used $\mathrm{P}<0.05$ as the criterion to screen DEGs between metastatic and non-metastatic ccRCC samples; using identical data, the present study screened the DEGs by stricter cut-off criteria [false discovery rate (FDR) $<0.05$ and $\mid \log$ fold change $(\mathrm{FC}) \mid>1$ ]. Subsequently, functional and pathway enrichment analysis was performed to predict the potential functions of DEGs. Furthermore, a protein-protein interaction (PPI) network was constructed to analyze the interactions between DEGs. In addition, small drug molecules associated with ccRCC were detected. It is anticipated that 
the results of the present study may lead to a potential breakthrough in the treatment of metastatic ccRCC.

\section{Materials and methods}

Microarray data. The microarray data GSE47352 deposited by Ni et al (6) was downloaded from the GEO (http://www.ncbi .nlm.nih.gov/geo/) of the National Center of Biotechnology Information. In addition, probes annotation information was also downloaded for mapping the probes to genes (https://www. ncbi.nlm.nih.gov/geo/query/acc.cgi?acc=GSE47352). This dataset was generated based on the platform of GPL570 (HG-U133_Plus_2) Affymetrix Human Genome U133 Plus 2.0 Array. A total of 9 samples are enrolled in the GSE47352 dataset, including 4 early metastatic ccRCC samples (metastatic group) and 5 non-metastatic ccRCC samples (non-metastatic group). The ccRCC tissue samples were removed from ccRCC patients who underwent nephrectomy at the Chinese People's Liberation Army General Hospital between January 2009 and May 2012, and were snap-frozen in liquid nitrogen. Patients with negative abdomen and chest computed tomography or magnetic resonance imaging and without metastatic lesions were classed as non-metastatic ccRCC; patients with metastatic lesions were classed as early metastatic ccRCC (6).

Data preprocessing and DEGs screening. Based on the k-Nearest Neighbors method (9), Affymetrix (Affy) package (version 1.28.0; Affymetrix, Inc., Santa Clara, CA, USA) (10) in $\mathrm{R}$ language was employed to account for the missing values in the raw data from the DNA microarray. Subsequently, the data was normalized by the median normalization method (11). Compared with the non-metastatic group, the DEGs in the metastatic group were screened using the linear model for microarray data (Limma) package (12). The Benjamini-Hochberg method (13) was applied to conduct multiple testing adjustment to identify the FDR and the $\log \mathrm{FC}$ was also calculated. Genes with $\mathrm{FDR}<0.05$ and $\mid \log \mathrm{FCl}>1$ were taken as the DEGs between the early metastatic and non-metastatic groups.

Comparison of gene expression between the metastatic and non-metastatic groups. Generally, significant differences in gene expression are observed in tissues under different disease states (14). The gene expression values of DEGs were extracted, and the pheatmap package (15) in $\mathrm{R}$ was used to perform two-way clustering (16) based on Euclidean distance (17).

Functional and pathway enrichment analysis. Gene map annotator and pathway profiler (GenMAPP; version 2.1; http:// www.GenMAPP.org) was used for visualizing, analyzing and demonstrating the microarray data in pathways (18). The MAPPFinder was used for coupling the annotations of the Gene Ontology (GO) database with GenMAPP and calculated the GO-values (19). In the present study, MAPPFinder and GenMAPP were employed separately to conduct functional and pathway enrichment analysis for the DEGs. $\mathrm{P}<0.05$ was taken as the threshold.

PPI network construction. The Search Tool for the Retrieval of Interacting Genes (STRING) database (http://string-db.org/) provided comprehensive predicted PPI information (20). The PPI pairs (combined score $>0.6$ ) were screened from the STRING database, and the PPI network was subsequently visualized using Cytoscape software (The Cytoscape Consortium, San Diego, CA, USA; version 2.8; http://www .cytoscape.org) (21).

Screening of small drug molecules. The Connectivity Map (cmap; http://www.broadinstitute.org/CMAP/) database may be used to investigate connections among small drug molecules, genes and diseases $(22,23)$. A higher negative score indicates a higher correlation between the small drug molecules and the DEGs. The DEGs were imported into cmap to screen the small drug molecules associated with DEGs. The small drug molecules with Iscorel $>0.8$ were recorded.

\section{Results}

DEGs screening. According to the microarray data analysis between early metastatic ccRCC and non-metastatic ccRCC samples by Limma, a total of 359 DEGs were obtained in metastatic group, including 196 upregulated genes and 163 downregulated genes. The top ten significantly upregulated (including vomeronasal 1 receptor 2 and homeobox A1) and downregulated [including epiregulin and RAR related orphan receptor A (RORA)] genes are listed in Table I.

Comparison of gene expression between metastatic and non-metastatic samples. Hierarchical cluster analysis of the expression values of DEGs revealed that the early metastatic ccRCC samples and the non-metastatic ccRCC samples were in significantly separated clusters (Fig. 1).

Functional and pathway enrichment analysis. A total of five Kyoto Encyclopedia Genes and Genomes pathways were obtained for the identified DEGs (Table II). The most significantly enriched pathway was the renal cell carcinoma pathway $(\mathrm{P}=0.003503)$, which involved 6 DEGs [endothelial PAS domain-containing protein 1 (EPAS1), ETS1, JUN, SOS2, TGF 32 , and protein tyrosine phosphatase, non-receptor type 11 (PTPN11)]. Furthermore, these 6 DEGs were all downregulated. In addition, 11 DEGs [including TGF $\beta 2$, nuclear receptor subfamily 4 group A member 1 (NR4A1) and dual specificity protein phosphatase 1 (DUSP1)] significantly participated in the mitogen-activate protein kinase (MAPK) signaling pathway $(\mathrm{P}=0.005407)$ and 5 DEGs [including laminin subunit $\alpha$ (LAMA) 2, LAMA1 and LAMA4] were enriched in the extracellular matrix (ECM)-receptor interaction pathway $(\mathrm{P}=0.034718)$.

The top 10 GO terms are listed in Table III, including regulation of transcription from RNA polymerase II promoter $\left(\mathrm{P}=7.26 \times 10^{-6}\right)$, positive regulation of the nucleic acid metabolic process $\left(\mathrm{P}=3.53 \times 10^{-5}\right)$ and positive regulation of the nitrogen compound metabolic process $\left(\mathrm{P}=5.82 \times 10^{-5}\right)$. In particular, JUN, EST1, RORA and TGF $\beta 2$ were significantly enriched in the majority of the GO terms.

PPI network construction. In total, 87 PPI pairs were obtained from the STRING database. Subsequently, the six DEGs (EPAS1, ETS1, JUN, SOS2, TGFß2 and PTPN11) that were 
Table I. Top ten up- and downregulated genes.

\begin{tabular}{|c|c|c|c|c|c|}
\hline \multicolumn{3}{|c|}{ Downregulated genes } & \multicolumn{3}{|c|}{ Upregulated genes } \\
\hline Gene symbol & FDR & $\operatorname{LogFC}$ & Gene symbol & FDR & $\operatorname{LogFC}$ \\
\hline EREG & 0.0106464 & -4.63294 & VN1R2 & 0.0060399 & 4.758334 \\
\hline CCDC158 & 0.0009937 & -4.13289 & TSPAN3 & 0.0078284 & 4.667987 \\
\hline HMGCLL1 & 0.0024176 & -4.12305 & KCTD4 & 0.0100570 & 4.158775 \\
\hline TRAF3IP2-AS1 & 0.0000508 & -4.10811 & CECR9 & 0.0089814 & 3.969089 \\
\hline RORA & 0.0056259 & -4.09241 & PCDH20 & 0.0034170 & 3.889183 \\
\hline TMEM51-AS1 & 0.0086847 & -3.87088 & FAM95A & 0.0082171 & 3.883404 \\
\hline LOC645485 & 0.0063110 & -3.86383 & SEZ6L & 0.0078182 & 3.846624 \\
\hline UNC93A & 0.0024362 & -3.85761 & CYLC1 & 0.0010110 & 3.833110 \\
\hline RGPD1 & 0.0034170 & -3.78002 & SLC22A25 & 0.0069844 & 3.821152 \\
\hline FAHD2CP & 0.0009937 & -3.75996 & HOXA1 & 0.0054553 & 3.815357 \\
\hline
\end{tabular}

FDR, false discovery rate; FC, fold change.

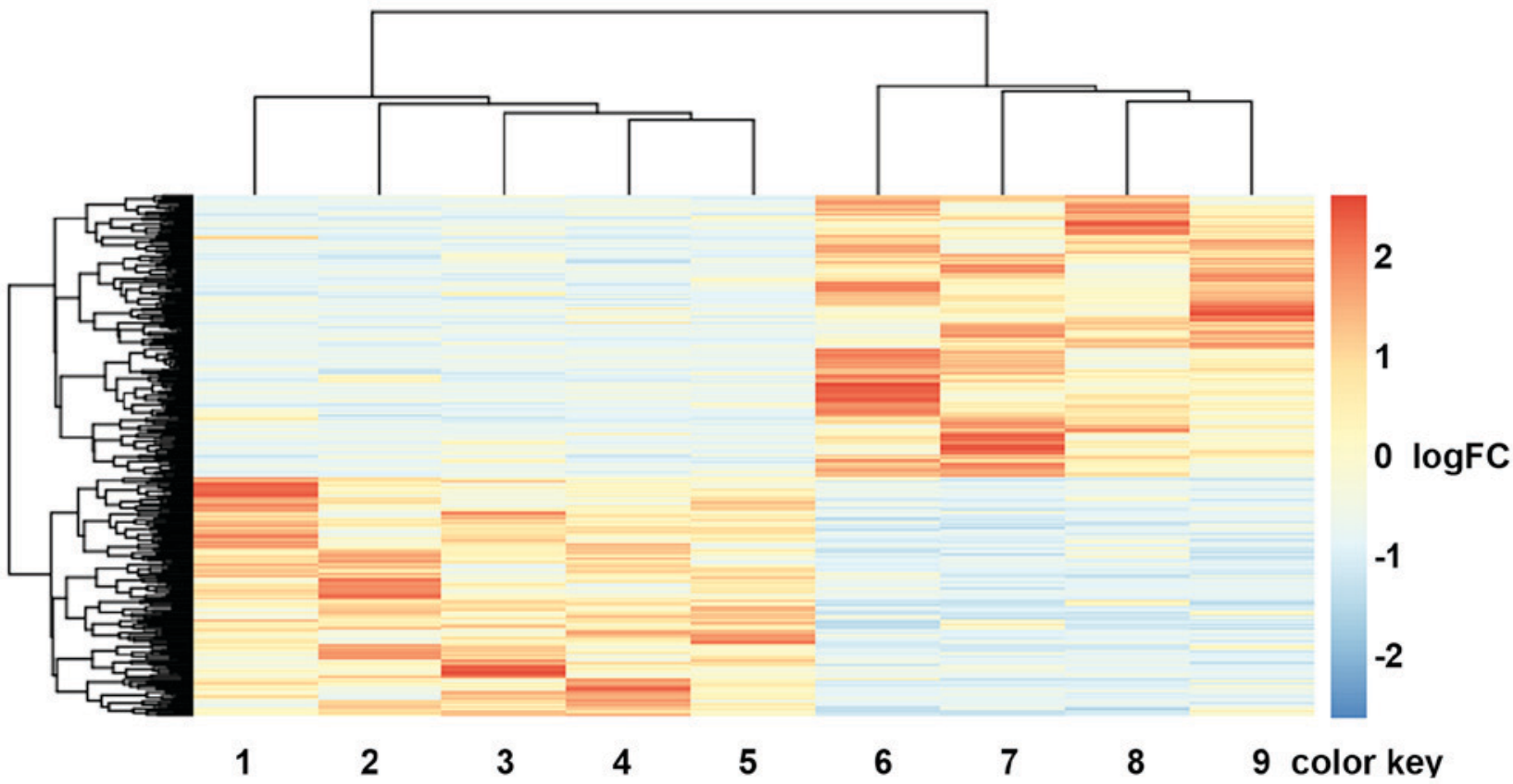

Figure 1. Two-way clustering of DEGs. The horizontal axis represents the samples (1-5: Non-metastatic ccRCC samples; 6-9: Metastatic ccRCC samples). The vertical axis represents the DEGs between non-metastatic and metastatic ccRCC samples. The color key represents the logFC of DEGs. FC, fold change; ccRCC, clear cell renal cell carcinoma.

enriched in the renal cell carcinoma pathway were mapped to the network. The network was visualized using Cytoscape (Fig. 2). In the PPI network, JUN possessed the highest degree of 6; additionally, ferritin light chain 1, NR4A1 and Ras homolog family member B (RHOB) demonstrated degrees of 5, 5 and 4, respectively. Furthermore, JUN could interact with ever shorter telomeres protein 1 (EST1), RHOB, DUSP1, tumor necrosis factor (TNF), MYC associated zinc finger protein (MAZ) and cyclin A1 (CCNA1). In addition, NR4A1 demonstrated an interaction with DUSP1.

Small drug molecule screening. For the screening of small molecular drugs, 7 small drug molecules with the $\mid$ scorel $>0.8$, including 4 negatively-correlated drugs (thapsigargin, score $=-0.913 ; \mathrm{W}-13$, score $=-0.885$; trihexyphenidyl, score $=-0.839$; and lovastatin, score $=-0.824$ ) and 3 positively-correlated drugs (dioxybenzone, score $=0.825$; oxybuprocaine, score $=0.853$; and $(-)-\mathrm{MK}-801$, score $=0.887$ ) were identified to be correlated with the DEGs (Table IV).

\section{Discussion}

In the present study, with the investigation of the gene expression profile between the early metastatic and non-metastatic ccRCC using bioinformatics methods, a total of 359 DEGs were obtained, including 196 upregulated DEGs 
Table II. Enriched pathways for differentially expressed genes between early metastasis ccRCC and the non-metastasis ccRCC samples.

Genes

\begin{tabular}{|c|c|c|c|c|c|}
\hline ID & Pathways & P-value & Count & Upregulated & Downregulated \\
\hline hsa05211 & $\begin{array}{l}\text { Renal cell } \\
\text { carcinoma }\end{array}$ & 0.003503 & 6 & - & $\begin{array}{l}\text { EPAS1, ETS1, JUN, TGF } 32, \\
\text { SOS2, PTPN11 }\end{array}$ \\
\hline hsa04010 & $\begin{array}{l}\text { MAPK signaling } \\
\text { pathway }\end{array}$ & 0.005407 & 11 & $\begin{array}{l}\text { CACNA2D1, TNF, } \\
\text { PTPN5, MAPK8IP3, } \\
\text { CACNG2 }\end{array}$ & $\begin{array}{l}\text { FGF8, DUSP1, JUN, } \\
\text { SOS2, NR4A1, TGF } 22\end{array}$ \\
\hline hsa05410 & $\begin{array}{l}\text { Hypertrophic } \\
\text { cardiomyopathy }\end{array}$ & 0.008004 & 6 & $\begin{array}{l}\text { CACNA2D1, TNF, } \\
\text { SGCD, CACNG2 }\end{array}$ & TGF 32 LAMA2 \\
\hline hsa05414 & $\begin{array}{l}\text { Dilated } \\
\text { cardiomyopathy }\end{array}$ & 0.011083 & 6 & $\begin{array}{l}\text { CACNA2D1, TNF, } \\
\text { SGCD, CACNG2 }\end{array}$ & TGF $\beta 2$, LAMA2, \\
\hline hsa04512 & $\begin{array}{l}\text { ECM-receptor } \\
\text { interaction }\end{array}$ & 0.034718 & 5 & SV2B & $\begin{array}{l}\text { LAMA2, LAMA1, LAMA4, } \\
\text { CD36 }\end{array}$ \\
\hline
\end{tabular}

ccRCC, clear cell renal cell carcinoma; MAPK, mitogen activated protein kinase; ECM, extracellular matrix.

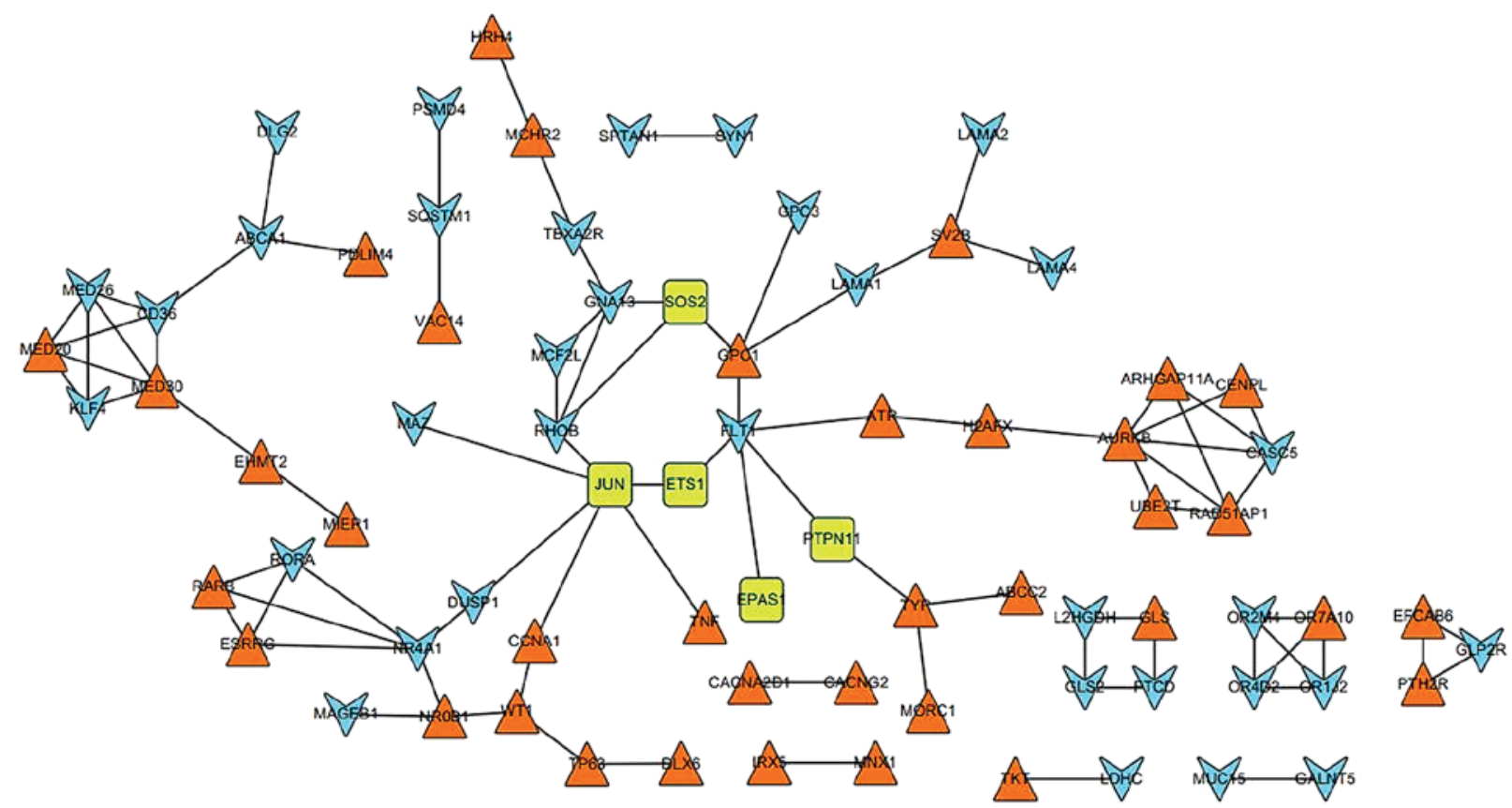

Figure 2. Protein-protein interaction network of the DEGs. Blue arrowheads and orange triangles represent the downregulated and upregulated genes, respectively. Green squares represent downregulated genes involved in the signaling pathway of renal cell carcinoma.

and 163 downregulated DEGs. Hierarchical cluster analysis indicated that the metastatic ccRCC samples could be well distinguished from the non-metastatic ccRCC samples according to the identified DEGs. Furthermore, pathway enrichment analysis revealed that JUN was significantly enriched in renal cell carcinoma and the MAPK signaling pathway. Previous research has proven that MAPK serves a key role in tumor metastasis via regulating cell migration and apoptosis (24). Furthermore, in the PPI network, JUN was a hub node with the highest degree of 6 and could interact with RHOB, MAZ, DUSP1, CCNA1, TNF and EST1. JUN is identified as oncogene, which accelerates tumor cell metastasis (25).
Zhang et al (26) demonstrated that JUN has a close association with metastasis of cancer cells, and overexpression of JUN may result in metastasis of breast cancer. A previous study demonstrated that epithelial-mesenchymal transition (EMT) is a key regulator of metastasis in cancer by conferring an invasive phenotype via the loss of cell-cell adhesions, cell-substrates and transition to a cell type that is capable of invading the ECM (27). Furthermore, EMT has been identified as a model by which the ccRCC occurs (28). In the present study, TNF and RHOB were significantly enriched in the pathway of early metastatic ccRCC. Previous studies have illustrated that TNF (or TNF- $\alpha$ ) is able to elevate the migration and invasion 
Table III. Top ten enriched functions for the differentially expressed genes.

\begin{tabular}{|c|c|c|c|c|}
\hline ID & Gene ontology term & Count & P-value & Genes \\
\hline GO:0006357 & $\begin{array}{l}\text { Regulation of } \\
\text { transcription from } \\
\text { RNA polymerase II } \\
\text { promoter }\end{array}$ & 29 & $7.26 \times 10^{-6}$ & $\begin{array}{l}\text { TNF, FOXK1, ONECUT2, NR6A1, FOXK2, TP63, RORA, } \\
\text { MED20, WT1, HOXA1, NPAS1, SQSTM1, MED26, HSF4, } \\
\text { RARB, DGKQ, KLF9, EPAS1, NR4A1, TEAD2, NR0B1, } \\
\text { IL22, SP2, ETS1, JUN, MNX1, TFAP2E, KLF4, NFIB }\end{array}$ \\
\hline GO:0045935 & $\begin{array}{l}\text { Positive regulation } \\
\text { of nucleic acid } \\
\text { metabolic process }\end{array}$ & 25 & $3.53 \times 10^{-5}$ & $\begin{array}{l}\text { TNF, FOXK1, ONECUT2, TP63, ABCA1, RORA, WT1, } \\
\text { HOXA1, SQSTM1, H2AFX, RARB, HSF4, EPAS1, TAF8, } \\
\text { ESRRG, NR4A1, TEAD2, IL22, EREG, IRF6, ETS1, JUN, } \\
\text { TFAP2E, KLF4, NFIB }\end{array}$ \\
\hline GO:0045893 & $\begin{array}{l}\text { Positive regulation } \\
\text { of transcription }\end{array}$ & 21 & $5.04 \times 10^{-5}$ & $\begin{array}{l}\text { TNF, EPAS1, FOXK1, TAF8, ONECUT2, ESRRG, TP63, } \\
\text { NR4A1, TEAD2, RORA, IL22, WT1, HOXA1, SQSTM1, } \\
\text { ETS1, JUN, RARB, HSF4, TFAP2E, KLF4, NFIB }\end{array}$ \\
\hline GO:0051254 & $\begin{array}{l}\text { Positive regulation } \\
\text { of RNA } \\
\text { metabolic process }\end{array}$ & 21 & $5.72 \times 10^{-5}$ & $\begin{array}{l}\text { TNF, EPAS1, FOXK1, TAF8, ONECUT2, ESRRG, TP63, } \\
\text { NR4A1, TEAD2, RORA, IL22, WT1, HOXA1, SQSTM1, } \\
\text { ETS1, JUN, RARB, HSF4, TFAP2E, KLF4, NFIB }\end{array}$ \\
\hline GO:0051173 & $\begin{array}{l}\text { Positive regulation of } \\
\text { nitrogen compound } \\
\text { metabolic process }\end{array}$ & 25 & $5.82 \times 10^{-5}$ & $\begin{array}{l}\text { TNF, FOXK1, ONECUT2, TP63, ABCA1, RORA, WT1, } \\
\text { HOXA1, SQSTM1, H2AFX, RARB, HSF4, EPAS1, TAF8, } \\
\text { ESRRG, NR4A1, TEAD2, IL22, EREG, IRF6, ETS1, JUN, } \\
\text { TFAP2E, KLF4, NFIB }\end{array}$ \\
\hline GO:0045944 & $\begin{array}{l}\text { Positive regulation of } \\
\text { transcription from RNA } \\
\text { polymerase II promoter }\end{array}$ & 18 & $6.37 \times 10^{-5}$ & $\begin{array}{l}\text { TNF, EPAS1, ONECUT2, TP63, NR4A1, TEAD2, RORA, } \\
\text { IL22, WT1, HOXA1, SQSTM1, ETS1, JUN, RARB, HSF4, } \\
\text { TFAP2E, KLF4, NFIB }\end{array}$ \\
\hline GO:0009891 & $\begin{array}{l}\text { Positive regulation } \\
\text { of biosynthetic } \\
\text { process }\end{array}$ & 26 & $7.16 \times 10^{-5}$ & $\begin{array}{l}\text { TNF, FOXK1, ONECUT2, TP63, APOC2, ABCA1, RORA, } \\
\text { WT1, TGFß2, HOXA1, SQSTM1, RARB, HSF4, EPAS1, } \\
\text { TAF8, ESRRG, NR4A1, TEAD2, IL22, EREG, IRF6, ETS1, } \\
\text { JUN, TFAP2E, KLF4, NFIB }\end{array}$ \\
\hline GO:0031328 & $\begin{array}{l}\text { Positive regulation of } \\
\text { cellular biosynthetic } \\
\text { process }\end{array}$ & 25 & $1.51 \mathrm{~s} 10^{-4}$ & $\begin{array}{l}\text { TNF, FOXK1, ONECUT2, TP63, APOC2, ABCA1, RORA, } \\
\text { WT1, HOXA1, SQSTM1, RARB, HSF4, EPAS1, TAF8, } \\
\text { ESRRG, NR4A1, TEAD2, IL22, EREG, IRF6, ETS1, JUN, } \\
\text { TFAP2E, KLF4, NFIB }\end{array}$ \\
\hline GO:0010557 & $\begin{array}{l}\text { Positive regulation of } \\
\text { macromolecule } \\
\text { biosynthetic process }\end{array}$ & 24 & $1.97 \times 10^{-4}$ & $\begin{array}{l}\text { TNF, EPAS1, FOXK1, TAF8, ONECUT2, ESRRG, TP63, } \\
\text { NR4A1, TEAD2, RORA, IL22, WT1, TGFß2, HOXA1, } \\
\text { EREG, IRF6, SQSTM1, ETS1, JUN, RARB, HSF4, TFAP2E, } \\
\text { KLF4, NFIB }\end{array}$ \\
\hline GO:0010628 & $\begin{array}{l}\text { Positive regulation } \\
\text { of gene expression }\end{array}$ & 22 & $2.62 \times 10^{-4}$ & $\begin{array}{l}\text { TNF, EPAS1, FOXK1, TAF8, ONECUT2, ESRRG, TP63, } \\
\text { NR4A1, TEAD2, RORA, IL22, WT1, HOXA1, IRF6, } \\
\text { SQSTM1, ETS1, JUN, RARB, HSF4, TFAP2E, KLF4, NFIB }\end{array}$ \\
\hline
\end{tabular}

of ccRCC cells together with downregulation of E-cadherin expression and promotion of EMT, suggesting that TNF has a close association with early metastatic ccRCC (29). RHOB is known as a tumor suppressor and is able to affect cell adhesion and migration by regulating surface integrin levels (30). Furthermore, it has also been observed that RHOB serves a distinct function in EMT by regulating cell-cell and cellsubstrate contact in renal proximal tubular cells, suggesting that RHOB has a key role in early metastatic ccRCC (31). This appears to indicate that JUN, along with the interaction with TNF and RHOB, may participate in mediation of early metastatic ccRCC via regulation of cell migration and apoptosis.

In addition, NR4A1 and TGF $\beta 2$ were significantly enriched in the MAPK signaling pathway. Previous research has demonstrated that the MAPK signaling pathway is involved in inhibition of tumorigenesis, metastasis and angiogenesis in RCC via the disruption of tumor vasculature (32). NR4A1, which belongs to the Nur nuclear receptor family, has been implicated in cell cycle regulation, inflammation and apoptosis (33). It has also been reported that NR4A1 is able to promote the invasion and metastasis of breast cancer by activating TGF $\beta$ signaling (34). Furthermore, the loss of NR4A1 may enhance macrophage-mediated kidney injury and diseases due to a large increase in immune cell infiltration (predominantly macrophages, and to a lesser extent $\mathrm{T}$ cells and B cells) (35). Therefore, the authors hypothesized that NR4A1 had a close association with early metastatic ccRCC. TGF $\beta 2$, which belongs to the TGF $\beta$ family, is known to 
Table IV. Small molecule drugs (Iscorel>0.8) associated with the differentially expressed genes between the primary metastatic ccRCC and the non-metastatic ccRCC samples.

\begin{tabular}{lcc}
\hline Connectivity map name & Score & P-value \\
\hline Thapsigargin & -0.913 & 0.00112 \\
W-13 & -0.885 & 0.02630 \\
Trihexyphenidyl & -0.839 & 0.00839 \\
Lovastatin & -0.824 & 0.00181 \\
Dioxybenzone & 0.825 & 0.00149 \\
Oxybuprocaine & 0.853 & 0.00070 \\
(-)-MK-801 & 0.887 & 0.00016 \\
\hline
\end{tabular}

ccRCC, clear cell renal cell carcinoma.

promote the invasion of tumor cells and allow metastasis to distant organs via induction of EMT, suppression of immune surveillance, promotion of angiogenesis and recruitment of inflammatory cells in human cancer cell lines and mouse tumor models $(36,37)$. Consequently, the present study speculated that NR4A1 and TGF 32 may serve a key role in the regulation of early metastatic ccRCC through the MAPK signaling pathway.

LAMA1, LAMA2 and LAMA4, which belong to the laminins family, were significantly enriched in the pathway of ECM-receptor interaction. Laminins, a family of ECM glycoproteins, are the major non-collagenous constituent of basement membranes (38). Laminins act as ECM fibers in lymph nodes, within which tumor cell metastasis occurs (39). A previous study has also reported that LAMA4 has a de-adhesive function and may serve a key role in detachment, migration and invasion of renal carcinoma cells in vivo (40). Therefore, LAMA1, LAMA2 and LAMA4 may be potential target genes in the treatment of early metastatic ccRCC.

Thapsigargin was discovered to have high efficiency for the treatment of early metastasis in ccRCC. Thapsigargin is a non-competitive inhibitor of sarco/endoplasmic reticulum $\mathrm{Ca}^{2+}$ ATPase (41). Thapsigargin is able to couple to a peptide carrier, producing a soluble non-toxic pro-drug, which induces apoptosis of prostate cancer cells (42). Research into the use of thapsigargin as a small drug molecule for cancer treatment has increased, including for the treatment of lung adenocarcinoma and prostate cancer $(42,43)$. Due to its positive effects on prostate cancer and lung adenocarcinoma, the present authors speculated that it may be also effective for the treatment of early metastatic ccRCC.

In conclusion, a total of 359 DEGs were identified in the metastatic group compared with the non-metastatic group. Furthermore, the DEGs, including TGF 32 , JUN, NR4A1, RHOB, LAMA1, LAMA2 and LAMA4, were involved in early metastatic ccRCC. In addition, the present study screened a small drug molecule named thapsigargin, which may have high efficiency for the treatment of the early metastatic ccRCC. However, further studies to investigate the viability of the above assumptions are required and additional experimental research is needed to validate the results of the present study, as well as confirm thapsigargin's safety and efficacy for the treatment of early metastatic ccRCC.

\section{Refereces}

1. Jemal A, Bray F, Center MM, Ferlay J, Ward E and Forman D: Global cancer statistics. CA Cancer J Clin 61: 69-90, 2011.

2. Rosner I, Bratslavsky G, Pinto PA and Linehan WM: The clinical implications of the genetics of renal cell carcinoma. Urol Oncol 27: 131-136, 2009.

3. Novara G, Ficarra V, Antonelli A, Artibani W, Bertini R, Carini M, Cosciani Cunico S, Imbimbo C, Longo N, et al: Validation of the 2009 TNM version in a large multi-institutional cohort of patients treated for renal cell carcinoma: Are further improvements needed? Eur Urol 58: 588-595, 2010.

4. Barrett T, Troup DB, Wilhite SE, Ledoux P, Evangelista C, Kim IF, Tomashevsky M, Marshall KA, Phillippy KH, Sherman PM, et al: NCBI GEO: Archive for functional genomics data sets-10 years on. Nucleic Acids Res 39 (Database Issue): D1005-D1010, 2011.

5. Parkinson H, Kapushesky M, Shojatalab M, Abeygunawardena N, Coulson R, Farne A, Holloway E, Kolesnykov N, Lilja P, Lukk M, et al: ArrayExpress-a public database of microarray experiments and gene expression profiles. Nucleic Acids Res 35 (Database issue): D747-D750, 2007.

6. Ni D, Ma X, Li HZ, Gao Y, Li XT, Zhang Y, Ai Q, Zhang P, Song EL, Huang QB, et al: Downregulation of FOXO3a promotes tumor metastasis and is associated with metastasis-free survival of patients with clear cell renal cell carcinoma. Clin Cancer Res 20: 1779-1790, 2014.

7. Mestas J, Burdick MD, Reckamp K, Pantuck A, Figlin RA and Strieter RM: The role of CXCR2/CXCR2 ligand biological axis in renal cell carcinoma. J Immunol 175: 5351-5357, 2005.

8. Tölle A, Jung M, Lein M, Johannsen M, Miller K, Moch H, Jung K and Kristiansen G: Brain-type and liver-type fatty acid-binding proteins: New tumor markers for renal cancer? BMC Cancer 9: 248, 2009.

9. Zhang ML and Zhou ZH: A k-nearest neighbor based algorithm for multi-label classification. Journal 2: 718-721, 2005.

10. Gautier L, Cope L, Bolstad BM and Irizarry RA: affy-analysis of Affymetrix GeneChip data at the probe level. Bioinformatics 20 : 307-315, 2004.

11. Rao Y, Lee Y, Jarjoura D, Ruppert AS, Liu CG, Hsu JC and Hagan JP: A comparison of normalization techniques for microRNA microarray data. Stat Appl Genet Mol Biol 7: Article22, 2008.

12. Gentleman R, Carey VJ, Huber W, Irizarry RA and Dudoit S: Bioinformatics and computational biology solutions using $\mathrm{R}$ and Bioconductor. Springer, 2005.

13. Genovese $\mathrm{C}$ and Wasserman L: Operating characteristics and extensions of the false discovery rate procedure. J Royal Statistical Soci Series B (Statistical Methodology) 64: 499-517, 2002.

14. Ester M, Kriegel HP, Sander J and Xu X: A density-based algorithm for discovering clusters in large spatial databases with noise. Journal 96: 226-231, 1996.

15. Kolde R: Pheatmap: Pretty Heatmaps. R Package Version 0.6.1. Journal, 2012.

16. Szekely GJ and Rizzo ML: Hierarchical clustering via joint between-within distances: Extending Ward's minimum variance method. J Classification 22: 151-183, 2005.

17. Deza MM and Deza E: Encyclopedia of Distances. Springer, 2009.

18. Dahlquist KD, Salomonis N, Vranizan K, Lawlor SC and Conklin BR: GenMAPP, a new tool for viewing and analyzing microarray data on biological pathways. Nat Genet 31: 19-20, 2002.

19. Doniger SW, Salomonis N, Dahlquist KD, Vranizan K, Lawlor SC and Conklin BR: MAPPFinder: Using gene ontology and GenMAPP to create a global gene-expression profile from microarray data. Genome Biol 4: R7, 2003.

20. Szklarczyk D, Franceschini A, Kuhn M, Simonovic M, Roth A, Minguez P, Doerks T, Stark M, Muller J, Bork P, et al: The STRING database in 2011: Functional interaction networks of proteins, globally integrated and scored. Nucleic Acids Res 39 (Database issue): D561-D568, 2011.

21. Smoot ME, Ono K, Ruscheinski J, Wang PL and Ideker T: Cytoscape 2.8: New features for data integration and network visualization. Bioinformatics 27: 431-432, 2011.

22. Lamb J: The Connectivity Map: A new tool for biomedical research. Nat Rev Cancer 7: 54-60, 2007.

23. Lamb J, Crawford ED, Peck D, Modell JW, Blat IC, Wrobel MJ, Lerner J, Brunet JP, Subramanian A, Ross KN, et al: The connectivity map: Using gene-expression signatures to connect small molecules, genes and disease. Science 313: 1929-1935, 2006. 
24. Reddy KB, Nabha SM and Atanaskova N: Role of MAP kinase in tumor progression and invasion. Cancer Metastasis Rev 22: 395-403, 2003.

25. Chaturvedi MM, Sung B, Yadav VR, Kannappan R and Aggarwal BB: NF- $\kappa$ B addiction and its role in cancer: 'One size does not fit all'. Oncogene 30: 1615-1630, 2010.

26. Zhang Y, Pu X, Shi M, Chen L, Song Y, Qian L, Yuan G, Zhang $\mathrm{H}, \mathrm{Yu} \mathrm{M}, \mathrm{Hu} \mathrm{M}$, et al: Critical role of c-Jun overexpression in liver metastasis of human breast cancer xenograft model. BMC Cancer 7: 145, 2007.

27. Davis FM, Stewart TA, Thompson EW and Monteith GR: Targeting EMT in cancer: Opportunities for pharmacological intervention. Trends Pharmacol Sci 35: 479-488, 2014.

28. Tun HW, Marlow LA, Von Roemeling CA, Cooper SJ, Kreinest P, Wu K, Luxon BA, Sinha M, Anastasiadis PZ and Copland JA: Pathway signature and cellular differentiation in clear cell renal cell carcinoma. PLoS One 5: e10696, 2010.

29. Mikami S, Mizuno R, Kosaka T, Saya H, Oya M and Okada Y: Expression of TNF- $\alpha$ and CD44 is implicated in poor prognosis, cancer cell invasion, metastasis and resistance to the sunitinib treatment in clear cell renal cell carcinomas. Int J Cancer 136 1504-1514, 2015.

30. Wheeler AP and Ridley AJ: RhoB affects macrophage adhesion, integrin expression and migration. Exp Cell Res 313: 3505-3516, 2007.

31. Hutchison N, Hendry BM and Sharpe CC: Rho isoforms have distinct and specific functions in the process of epithelial to mesenchymal transition in renal proximal tubular cells. Cell Signal 21: 1522-1531, 2009

32. Huang D, Ding Y, Luo WM, Bender S, Qian CN, Kort E, Zhang ZF, VandenBeldt K, Duesbery NS, Resau JH and Teh BT: Inhibition of MAPK kinase signaling pathways suppressed renal cell carcinoma growth and angiogenesis in vivo. Cancer Res 68 : 81-88, 2008

33. Pei L, Castrillo A and Tontonoz P: Regulation of macrophage inflammatory gene expression by the orphan nuclear receptor Nur77. Mol Endocrinol 20: 786-794, 2006.
34. Zhou F, Drabsch Y, Dekker TJ, de Vinuesa AG, Li Y, Hawinkels LJ, Sheppard KA, Goumans MJ, Luwor RB, de Vries CJ, et al: Nuclear receptor NR4A1 promotes breast cancer invasion and metastasis by activating TGF- $\beta$ signalling. Nat Commun 5: 3388, 2014.

35. Westbrook L, Johnson AC, Regner KR, Williams JM, Mattson DL, Kyle PB, Henegar JR and Garrett MR: Genetic susceptibility and loss of Nr4a1 enhances macrophage-mediated renal injury in CKD. J Am Soc Nephrol 25: 2499-2510, 2014.

36. Janda E, Lehmann K, Killisch I, Jechlinger M, Herzig M, Downward J, Beug H and Grünert S: Ras and TGF[beta] cooperatively regulate epithelial cell plasticity and metastasis Dissection of Ras signaling pathways. J Cell Biol 156: 299-313, 2002.

37. Heldin $\mathrm{C}-\mathrm{H}$, Vanlandewijck $\mathrm{M}$ and Moustakas A: Regulation of EMT by TGF $\beta$ in cancer. FEBS Lett 586: 1959-1970, 2012.

38. Hohenester E and Yurchenco PD: Laminins in basement membrane assembly. Cell Adh Migr 7: 56-63, 2013.

39. Patarroyo M, Tryggvason $\mathrm{K}$ and Virtanen I: Laminin isoforms in tumor invasion, angiogenesis and metastasis. Semin Cancer Biol 12: 197-207, 2002.

40. Vainionpää N, Lehto VP, Tryggvason K and Virtanen I: Alpha4 chain laminins are widely expressed in renal cell carcinomas and have a de-adhesive function. Lab Invest 87: 780-791, 2007.

41. Rogers TB, Inesi G, Wade R and Lederer W: Use of thapsigargin to study $\mathrm{Ca} 2+$ homeostasis in cardiac cells. Biosci Rep 15: 341-349, 1995.

42. Denmeade SR, Jakobsen CM, Janssen S, Khan SR, Garrett ES, Lilja H, Christensen SB and Isaacs JT: Prostate-specific antigen-activated thapsigargin prodrug as targeted therapy for prostate cancer. J Natl Cancer Inst 95: 990-1000, 2003.

43. Doan NT, Paulsen ES, Sehgal P, Møller JV, Nissen P, Denmeade SR, Isaacs JT, Dionne CA and Christensen SB: Targeting thapsigargin towards tumors. Steroids 2014. 